\title{
Role of fasting and postprandial hypertriglyceridemia and its association with carotid intima media thickness in Type II diabetes patients
}

\author{
R Pathak ${ }^{1}$, Prabin Adhikari², U. N. Pathak ${ }^{3}$ \\ Department of radiology1, Department of Medicine ${ }^{2,3}$, Nepal Medical College Teaching Hospital, Attarkhel, Jorpati, Kathmandu, Nepal
}

DOI Name

http://dx.doi.org/10.3126/jaim.v7i1.19578

\section{Keywords}

Diabetes Mellitus, Postprandial triglycerides, Carotid intima media thickness, Atherosclerosis.

\section{Citation}

R Pathak, Prabin Adhikari, U. N. Pathak. Role of fasting and postprandial hypertriglyceridemia and its association with carotid intima media thickness in Type II diabetes patients. Journal of Advances in Internal Medicine 2017;06(01):17-22.

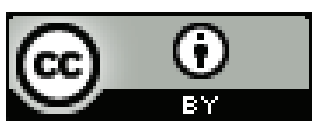

This work is licensed under a Creative Commons Attribution 3.0 Unported License.

\begin{abstract}
Background and aim: Type 2 diabetes mellitus is associated with the development of premature arteriosclerosis and a higher cardiovascular morbidity and mortality. Diabetic dyslipidaemia is believed to play an important role in the pathogenesis of accelerated atherosclerosis in this condition. B-mode ultrasound enables noninvasive, direct visualization of the arterial wall. The aim of this study was to correlate intima media thickness of the carotid artery (CIMT) quantification as a reliable marker of atherosclerotic burden in diabetes patients.

Method: It was a Cross Sectional Study done on 50 patients in the age group of 30-70 years with type II Diabetes Mellitus of more than 5 years duration without hypertension. Carotid Intima Media Thickness (CIMT) was measured using an echotomographic system with a 7.5-MHz linear transducer probe. With the carotid bulb and the longitudinal projection of the common carotid artery $2 \mathrm{cmx}$ from carotid bulb, the site of the greatest thickness including a plaque lesion was sought along both near and far walls bilaterally.

Results: The mean CIMT of subjects with fasting triglyceride level less than $150 \mathrm{mg} /$ $\mathrm{dL}$ was $13.2 \pm 0.48 \mathrm{~mm}$ with a range of 0.6-2.4 $\mathrm{mm}$. Similarly the level between 150$200 \mathrm{mg} / \mathrm{dL}$ was $1.89 \pm 0.54 \mathrm{~mm}$ with a range of $1.3-2.6 \mathrm{~mm}$ and level more than 200 $\mathrm{mg} / \mathrm{dL}$ was $2.00 \pm 0.63 \mathrm{~mm}$ with a range of $0.8-2.6 \mathrm{~mm}$. From the present study, it is clearly evident that age, duration of disease, fasting triglycerides and postprandial triglycerides have a significant impact on the CIMT, whereas other variables are having any significant impact on CIMT.

Conclusion: The present study concludes both fasting and postprandial triglyceride levels correlate significantly with carotid intima media thickness. But, the correlation of postprandial triglyceride levels with carotid intima media thickness is better than that of fasting triglyceride levels with carotid intima media thickness, the postprandial hypertriglyceridemia despite normal fasting triglyceride level can be considered as an independent risk factor for atherosclerosis in type 2 diabetes mellitus.
\end{abstract}

\section{INTRODUCTION}

The term diabetes in Greek mean 'running through' was first described by Aretaeus of Cappadocia in second century AD. Ancient Indian system of medicine (600-400 BC) like Charak and Sushruta, were versed with many of the currently known facts of the disease and named it 'madhumeha'. ${ }^{[1]}$

The worldwide prevalence of DM has risen dramatically over the past two decades. Although the prevalence of both type 1 and type $2 \mathrm{BM}$ is increasing worldwide, the prevalence of type $2 \mathrm{DM}$ is rising much rapidly. ${ }^{[2]}$

It has been suggested that every year there are 4 million deaths due to diabetes, and today 285 million people across the world are living with diabetes. ${ }^{[3]}$

These numbers are projected to increase to 333 and 472 million, respectively, by the year 2025. ${ }^{[4]}$

Diabetes is a fascinating condition since insulin deficiency leads to such a marked disturbance in metabolism. Although traditionally diabetes has been thought of as a group of common metabolic disorders that share the phenotype of hyperglycemia, it is clear that the disruption in fatty acid metabolism may be far more important in genesis of atherosclerosis in both type 1 and 2 diabetes. ${ }^{[3]}$

Type 2 diabetes mellitus is associated with the development of premature arteriosclerosis and a higher cardiovascular morbidity and mortality. ${ }^{[5-7]}$

Diabetic dyslipidaemia is believed to play an important role in the pathogenesis of accelerated atherosclerosis in this condition. ${ }^{[8,9]}$

Lipid abnormalities in type 2 diabetes are characterized by high triglyceride concentration, particularly post-prandially (post-prandial), high density lipoprotein-cholesterol (HDL)

\footnotetext{
* Corresponding author

Dr. Roshani Pathak

Department of Radiology

Nepal Medical College Teaching Hospital,

Attarkhel, Jorpati, Kathmandu, Nepal

Email: drroshanipathak@yahoo.co.in
} 
concentrations and normal total and low density lipoproteincholesterol (LDL) concentration. ${ }^{[10]}$

B-mode ultrasound enables non-invasive, direct visualization of the arterial wall. The intima media thickness of the carotid artery (CIMT) quantified using this technique, is a reliable marker of atherosclerotic burden.

Furthermore, it demonstrate greater sensitivity in detecting early atherosclerosis compared with angiography. ${ }^{[13]}$

\section{MATERIALS AND METHODS}

It was Cross Sectional Study done on 50 patients in the age group of 30-70 years with type II Diabetes Mellitus of more than 5 years duration without hypertension, admitted to Nepal Medical College and Hospital, Jorpati, Kathmandu, formed the material of the present study.

The study was approved by ethical committee of Nepal Medical College and Hospital, Jorpati, Kathmandu.

The exclusion criteria were patients with type 1diabetes mellitus, with age less than 30 and more than 70 years, with previous history of hypertension, stroke, IHD and peripheral vascular disease, and other secondary causes of type 2 diabetes mellitus and duration of diabetes from initial diagnosis $<5$ years.

Current designation of high triglyceride level-

$<150 \mathrm{mg} \%$ - Normal

150-199mg \% - Boarderline

200-499mg \% - High

$>500 \mathrm{mg} \%$ - Very high

We divided subjects into 3 categories based on above classification but grouped together high and very high. ${ }^{[1]}$

Carotid Intima Media Thickness (CIMT) was measured using an echotomographic system (TOSHIBA NEMIO 17) with a 7.5$\mathrm{MHz}$ linear transducer probe. With the carotid bulb and the longitudinal projection of the common carotid artery $2 \mathrm{cmx}$ from carotid bulb, the site of the greatest thickness including a plaque lesion was sought along both near and far walls bilaterally. (Lars A et al, 1971 ${ }^{[13]}$; Iglesias del Sol A et al, 2002 ${ }^{[12]}$ )

\section{STATISTICAL ANALYSIS}

Analysis of variance (ANOVA), $F$, has been used to find the significance of study parameters between $\mathrm{NN}, \mathrm{NH}$ and $\mathrm{HH}$. To compare means of two groups, students't' test was used with appropriate degrees of freedom and levels of significance. P-value which measures the probability was used at necessary places. P-value of greater than 0.05 was considered significant. Pearson correlation coefficient, $r$, a measure of the strength of the linear relationship between two variables was also used.

The statistical software namely SPSS 17.0 was used for the analysis of the data and Microsoft word and Excel have been used to generate graphs, tables, etc.

\section{RESULT}

Table No. 1: Distribution of Patients Based on FTG and PPTG

\begin{tabular}{|c|c|c|c|}
\hline Group & Classification & Number & $\%$ \\
\hline 1 & $\begin{array}{l}\text { Normo-Normo Group (NN) } \\
\text { (FTG } \leq 150 \mathrm{mg} / \mathrm{dL} \text { ) } \\
\text { PPTG } \leq 150 \mathrm{mg} / \mathrm{dL} \text { ) }\end{array}$ & 16 & 32 \\
\hline II & $\begin{array}{l}\text { Normo-Hyper Group (NH) } \\
\text { (FTG } \leq 150 \mathrm{mg} / \mathrm{dL} \text { ) } \\
\text { PPTG > } 150 \mathrm{mg} / \mathrm{dL} \text { ) }\end{array}$ & 18 & 36 \\
\hline III & $\begin{array}{l}\text { Hyper-Hyper Group (HH) } \\
\text { (FTG }>150 \mathrm{mg} / \mathrm{dL} \text { ) } \\
\text { PPTG }>150 \mathrm{mg} / \mathrm{dL} \text { ) }\end{array}$ & 16 & 32 \\
\hline Total & & 50 & 100 \\
\hline
\end{tabular}

Out of the 50 patients, 16 (32\%) were in the NN groups, 18 $(36 \%)$ in the $\mathrm{NN}$ group and $16(32 \%)$ in the $\mathrm{HH}$ group

Table No. 2: Assessment of Mean Fasting Triglyceride Levels According to Groups

\begin{tabular}{|c|c|c|c|}
\hline \multirow[b]{2}{*}{ Group } & \multirow[b]{2}{*}{ Classification } & \multicolumn{2}{|c|}{ FTG (mg/dL) } \\
\hline & & Range & Mean \pm SD \\
\hline I & $\begin{array}{l}\text { Normo-Normo Group (NN) } \\
\text { (FTG } \leq 150 \mathrm{mg} / \mathrm{dL} \text { ) } \\
\text { PPTG } \leq 150 \mathrm{mg} / \mathrm{dL} \text { ) }\end{array}$ & $33-136$ & $89.7 \pm 29$ \\
\hline II & $\begin{array}{l}\text { Normo-Hyper Group (NH) } \\
\text { (FTG } \leq 150 \mathrm{mg} / \mathrm{dL} \text { ) } \\
\text { PPTG }>150 \mathrm{mg} / \mathrm{dL} \text { ) }\end{array}$ & $59-143$ & $\begin{array}{c}107.4 \pm \\
24.7\end{array}$ \\
\hline \multicolumn{2}{|c|}{\begin{tabular}{l}
\multicolumn{1}{l}{ III } \\
Hyper-Hyper Group (HH) \\
(FTG > $150 \mathrm{mg} / \mathrm{dL}) ;$ \\
PPTG > $150 \mathrm{mg} / \mathrm{dL}$ )
\end{tabular}} & $155-433$ & $\begin{array}{c}237.3 \pm \\
81.9\end{array}$ \\
\hline
\end{tabular}

The mean serum fasting triglyceride in the NN group was $89.7 \pm 29 \mathrm{mg} / \mathrm{dL}$ with a range of $33-136 \mathrm{mg} / \mathrm{dL}$, Similarly, in the $\mathrm{NH}$ group was $107.4 \pm 24.7 \mathrm{mg} / \mathrm{dL}$ with a range of $59-143 \mathrm{mg} /$ $\mathrm{dL}$ and in the $\mathrm{HH}$ group was $237.3 \pm 81.9 \mathrm{mg} / \mathrm{dL}$ with a range of $155-433 \mathrm{mg} / \mathrm{dL}$.

Table No. 3: Assessment of Postprandial Triglyceride Levels According to Groups

\begin{tabular}{|c|c|c|c|}
\hline \multirow[b]{2}{*}{ Group } & \multirow[b]{2}{*}{ Classification } & \multicolumn{2}{|c|}{ FTG (mg/dL) } \\
\hline & & Range & Mean \pm SD \\
\hline 1 & $\begin{array}{l}\text { Normo-Normo Group (NN) } \\
\text { (FTG } \leq 150 \mathrm{mg} / \mathrm{dL} \text { ) } \\
\text { PPTG } \leq 150 \mathrm{mg} / \mathrm{dL} \text { ) }\end{array}$ & $43-147$ & $114.9 \pm 28.2$ \\
\hline II & $\begin{array}{l}\text { Normo-Hyper Group (NH) } \\
\text { (FTG } \leq 150 \mathrm{mg} / \mathrm{dL} \text { ) } \\
\text { PPTG }>150 \mathrm{mg} / \mathrm{dL} \text { ) }\end{array}$ & $156-317$ & $192.7 \pm 38.3$ \\
\hline III & $\begin{array}{l}\text { Hyper-Hyper Group (HH) } \\
\text { (FTG }>150 \mathrm{mg} / \mathrm{dL}) ; \\
\text { PPTG }>150 \mathrm{mg} / \mathrm{dL} \text { ) }\end{array}$ & $176-462$ & $289.1 \pm 87.9$ \\
\hline
\end{tabular}

The mean serum postprandial triglyceride in the $\mathrm{NN}$ group was $114.9 \pm 28.2 \mathrm{mg} / \mathrm{dL}$ with a range of $43-147 \mathrm{mg} / \mathrm{dL}$, the 
mean serum postprandial triglyceride in the $\mathrm{NH}$ group was $192.7 \pm 38.3 \mathrm{mg} / \mathrm{dL}$ with a range of $156-317 \mathrm{mg} / \mathrm{dL}$ and the mean serum postprandial triglyceride in the $\mathrm{HH}$ group was $289.1 \pm 87.9 \mathrm{mg} / \mathrm{dL}$ with a range of $176-462 \mathrm{mg} / \mathrm{dL}$.

Table No. 4: Assessment of CIMT According to Groups

\begin{tabular}{|c|c|c|c|}
\hline \multirow[b]{2}{*}{ Group } & \multirow[b]{2}{*}{ Classification } & \multicolumn{2}{|c|}{ CIMT (mm) } \\
\hline & & Range & Mean \pm SD \\
\hline I & $\begin{array}{l}\text { Normo-Normo Group (NN) } \\
\text { (FTG } \leq 150 \mathrm{mg} / \mathrm{dL} \text { ) } \\
\text { PPTG } \leq 150 \mathrm{mg} / \mathrm{dL} \text { ) }\end{array}$ & $0.6-1.6$ & $0.96 \pm 0.26$ \\
\hline II & $\begin{array}{l}\text { Normo-Hyper Group (NH) } \\
\text { (FTG } \leq 150 \mathrm{mg} / \mathrm{dL} \text { ) } \\
\text { PPTG > } 150 \mathrm{mg} / \mathrm{dL} \text { ) }\end{array}$ & $0.9-2.4$ & $1.64 \pm 0.39$ \\
\hline III & $\begin{array}{l}\text { Hyper-Hyper Group (HH) } \\
\text { (FTG > } 150 \mathrm{mg} / \mathrm{dL} \text { ); } \\
\text { PPTG > } 150 \mathrm{mg} / \mathrm{dL} \text { ) }\end{array}$ & $1.2-2.8$ & $1.94 \pm 0.57$ \\
\hline
\end{tabular}

In the NN group, the mean CIMT was $0.96 \pm 0.26 \mathrm{~mm}$ with a range of 0.6-1.6 mm. Similarly, in the NH group, the mean CIMT was $1.64 \pm 0.39 \mathrm{~mm}$ with a range of $0.9-2.4 \mathrm{~mm}$ and in the $\mathrm{HH}$ group, the mean CIMT was $1.94 \pm 0.57 \mathrm{~mm}$ with a range of 1.2 $2.8 \mathrm{~mm}$.

Table No. 5: Assessment of CIMT According to Fasting Triglycerides Levels

\begin{tabular}{lcc}
\hline \multicolumn{2}{c}{ Fasting Triglycerides Levels } & \multicolumn{2}{c}{ CIMT (mm) } \\
\multicolumn{1}{c}{$(\mathrm{mg} / \mathrm{dL})$} & Range & Mean \pm SD \\
\hline$<150$ & $0.6-2.4$ & $1.32 \pm 0.48$ \\
$150-200$ & $1.3-2.6$ & $1.89 \pm 0.54$ \\
$>200$ & $1.2-2.8$ & $2.0 \pm 0.63$ \\
\hline
\end{tabular}

The mean CIMT of subjects with fasting triglyceride level less than $150 \mathrm{mg} / \mathrm{dL}$ was $13.2 \pm 0.48 \mathrm{~mm}$ with a range of $0.6-2.4$ $\mathrm{mm}$. Similarly the level between $150-200 \mathrm{mg} / \mathrm{dL}$ was $1.89 \pm 0.54$ $\mathrm{mm}$ with a range of 1.3-2.6 mm and level more than $200 \mathrm{mg} / \mathrm{dL}$ was $2.00 \pm 0.63 \mathrm{~mm}$ with a range of 0.8-2.6 $\mathrm{mm}$.

Table No. 6: Assessment of CIMT According to Postprandial Triglycerides Levels

\begin{tabular}{lcc}
\hline \multicolumn{2}{c}{ Postprandial Triglycerides Levels } & \multicolumn{2}{c}{ CIMT (mm) } \\
\multicolumn{1}{c}{$(\mathrm{mg} / \mathrm{dL})$} & Range & Mean \pm SD \\
\hline$<150$ & $0.6-1.6$ & $0.96 \pm 0.26$ \\
$150-200$ & $0.9-2.4$ & $1.67 \pm 0.42$ \\
$>200$ & $1.2-2.8$ & $1.87 \pm 0.55$ \\
\hline
\end{tabular}

The mean CIMT of subjects with postprandial triglyceride level less than $150 \mathrm{mg} / \mathrm{dL}$ was $0.96 \pm 0.26 \mathrm{~mm}$ with a range of 0.6-1.6 $\mathrm{mm}$, the level between $150-200 \mathrm{mg} / \mathrm{dL}$ was $1.67 \pm 0.42 \mathrm{~mm}$ with a range of 0.9-2.4 mm. and the level more than $200 \mathrm{mg} /$ $\mathrm{dL}$ was $1.87 \pm 0.55 \mathrm{~mm}$ with a range of $1.2-2.8 \mathrm{~mm}$.
Table No. 7: Distribution of Postprandial Triglyceride Levels with CIMT in Patients with Normal Fasting Triglyceride Levels

\begin{tabular}{lcc}
\hline \multicolumn{1}{c}{$\begin{array}{c}\text { Fasting Triglyceride Levels and Post- } \\
\text { prandial Triglyceride Levels }\end{array}$} & \multicolumn{2}{c}{ CIMT $(\mathrm{mm})$} \\
& Range & Mean \pm SD \\
\hline FTG $\leq 150 \mathrm{mg} / \mathrm{dL} ;$ & $0.6-1.6$ & $0.96 \pm 0.26$ \\
PPTG $\leq 150 \mathrm{mg} / \mathrm{dL}$ & & \\
FTG $\leq 150 \mathrm{mg} / \mathrm{dL} ;$ & $0.9-2.4$ & $1.63 \pm 0.38$ \\
PPTG between $150-200 \mathrm{mg} / \mathrm{dL}$ & & \\
FTG $\leq 150 \mathrm{mg} / \mathrm{dL} ;$ & $1.2-2.4$ & $1.64 \pm 0.46$ \\
PPTG $>200 \mathrm{mg} / \mathrm{dL}$ & & \\
\hline
\end{tabular}

The mean CIMT of subjects with normal fasting and normal postprandial triglyceride level less than $150 \mathrm{mg} / \mathrm{dL}$ was $0.96 \pm 0.26 \mathrm{~mm}$ with a range of 0.6-1.6 $\mathrm{mm}$. Similarly the level between $150-200 \mathrm{mg} / \mathrm{dL}$ was $1.63 \pm 0.38 \mathrm{~mm}$ with a range of $0.9-2.4 \mathrm{~mm}$. and the level more than $200 \mathrm{mg} / \mathrm{dL}$ was $1.64 \pm 0.46$ $\mathrm{mm}$ with a range of 1.2-2.4 $\mathrm{mm}$.

Table No. 8: Comparative Analysis of CIMT with Various Variable Under Study

\begin{tabular}{lccl}
\hline \multicolumn{1}{c}{ Variable } & ' $r$ ' value & ' $\mathrm{p}$ ' value & Significance \\
\hline Age & 0.324 & $\mathrm{P}<0.05$ & Significant \\
Duration & 0.456 & $\mathrm{P}<0.01$ & Highly Significant \\
FBS & 0.041 & $\mathrm{P}>0.05$ & Not Significant \\
PPBS & 0.442 & $\mathrm{P}<0.05$ & Significant \\
Cholesterol-fasting & 0.08 & $\mathrm{P}>0.05$ & Not Significant \\
Cholesterol-post prandial & 0.00 & $\mathrm{P}>0.05$ & Not Significant \\
LDL-fasting & 0.00 & $\mathrm{P}>0.05$ & Not Significant \\
LDL-post prandial & -0.13 & $\mathrm{P}>0.05$ & Not Significant \\
HDL-fasting & -0.247 & $\mathrm{P}>0.05$ & Not Significant \\
HDL-post prandial & -0.241 & $\mathrm{P}>0.05$ & Not Significant \\
VLDL-fasting & 0.436 & $\mathrm{P}<0.05$ & Significant \\
VLDL-post prandial & 0.357 & $\mathrm{P}<0.05$ & Significant \\
Triglyceride-fasting & 0.45 & $\mathrm{P}<0.001$ & Highly Significant \\
Triglyceride -post prandial & 0.67 & $\mathrm{P}<0.001$ & Highly Significant \\
\hline
\end{tabular}

From the present study, it is clearly evident that age, duration of disease, fasting triglycerides and postprandial triglycerides have a significant impact on the CIMT, whereas other variables are having any significant impact on CIMT.

\section{DISCUSSION}

The present study was conducted at Nepal Medical College, Kathmandu and included 50 patients having type 2 diabetes mellitus for more than 5 years duration.

The patients were divided into three groups based on the fasting and postprandial triglyceride levels. The first group is normo-normo (NN) group $(n=16)$, i.e. the patients having normal fasting and normal postprandial triglyceride levels. Second group is normo-hyper $(\mathrm{NH})$ group $(n=18)$, i.e. the patient having normal fasting but high postprandial triglyceride 
levels. Third group is hyper-hyper $(\mathrm{HH})$ group $(n=16)$, i.e. the patients with high fasting and high postprandial triglyceride levels.

The distribution of the patients in the $\mathrm{NN}, \mathrm{NH}$ and $\mathrm{HH}$ groups in the present study was exactly similar to that in the studies of ShinchiTeno et al $^{[14]}$ in 2000 involving 61 and Ahmad J et al ${ }^{[15]}$ in 2005 involving 86 patients.

The patients included in the present study aged between 35 70 years. The mean age of the subjects was $54,64 \pm 9.53$ years. Majority (32\%) of the patients were in the age group of 51-60 years. The mean age of the patients in NN group was $57.75 \pm$ 7.86 years. $\mathrm{NH}$ group was $53.94 \pm 10.49$ years and $\mathrm{HH}$ group was $52.31 \pm 9.67$ years. These observations were similar to the study of ShinchiTeno et al $^{[14]}$ in 2000 where it was found that age of the patients ranged from 35-69 years. The mean age of patients was $53.7 \pm 7.2$ years. The mean age in the NN, $\mathrm{NH}$ and $\mathrm{HH}$ group was $52.5 \pm 6.2,54.7 \pm 9.1,54.9 \pm 7.7$ years respectively.

ShinchiTeno et al[14] in 2000 studied 61 patients and out of them, 40 (65\%) were males and rest (35\%) were females. In majority of other studies also, there was a male predominance. However, in the present study of 50 patients, 26 (52\%) were females and $24(48 \%)$ were males. More or less, there was equal predominance as the patients were randomly selected. Similar observations were found in the study of Mala Dharmalingam et al ${ }^{[16]}$ in 2004, in which out of 145 patients, female comprised 74 (51\%) patients and males comprised 71 (49\%) patients where the predominance was similar in either sex.

The duration of diabetes mellitus from initial diagnosis varied from 5 to 25 years and the mean duration of diabetes was $8.16 \pm 4.13$ years. The majority of the patients $42(84 \%)$ had diabetes since $11-15$ years. The mean duration of diabetes in the $\mathrm{NN}, \mathrm{NH}, \mathrm{HH}$ group was $9.75 \pm 5.72,6.28 \pm 1.84$ and $8.69 \pm$ 3.46 years respectively.

ShinchiTeno et al ${ }^{[14]}$ in 2000 , found that the mean duration of diabetes from initial diagnosis was $7.2 \pm 5.8$ years. The mean duration of diabetes in NN, $\mathrm{NH}$ and $\mathrm{HH}$ groups was $7.8 \pm 5.4$, $4.8 \pm 3.4$ and $7.8 \pm 7.4$ years. These observations are more or less similar to that of the present study.

The mean CIMT in the NN, NH and $\mathrm{HH}$ group was $0.96 \pm 0.26$, $1.64 \pm 0.39$ and $1.94 \pm 0.57 \mathrm{~mm}$ respectively. The CIMT was higher in the $\mathrm{NH}$ and $\mathrm{HH}$ groups in comparison with that in the NN group which is statistically significant $(p<0.001)$. This is consistent with the study of ShinchiTeno et al ${ }^{[14]}$ in 2000 , who observed that CIMT was significantly higher in the $\mathrm{NH}$ and $\mathrm{HH}$ groups than in NN group $(p<0.01)$.

It was observed that the age of the patient advances, the CIMT also increases. The age of the patient was found to be significantly associated with the CIMT $(r=0.32, p<0.05)$. similar observation were obtained in the studies of Ahmad J et al ${ }^{[15]}$ in 2005, Mohan V et al $^{[17]}$ in 2000, Katherine Esposito et al $^{[18]}$ in 2008 and Abdelghaffer $\mathbf{S}$ et al ${ }^{[19]}$ in 2006, who found that CIMT correlated positively with age of the subjects $(r=0.76, p<0.05)$.

The duration of the diabetes was found to be significantly correlating with the CIMT ( $r=0.456, p<0.001)$. this correlation is in accordance with the study of Abdelghaffer $S$ et al ${ }^{[19]}$ in
2005, where significant correlation was found between CIMT and duration of disease in diabetic patients $(r=0.66, p<0.001)$ Mohan $\mathbf{V}$ et $\mathbf{a l}^{[17]}$ in 2000 also found more or less identical results.

The mean FBS in the NN, NH and $\mathrm{HH}$ groups was $157.3 \pm$ 109.7, $184.1 \pm 112.8$ and $214.4 \pm 120.8 \mathrm{mg} / \mathrm{dl}$ respectively. There was no statistical correlation between the FBS and CIMT $(r=0.04, p<0.05)$. this observation was similar to that observed by KatherineEsposito et al $^{[18]}$ in 2008 , where it was reported that CIMT did not correlate with fasting glucose levels $(r=0.14$, $p<0.05)$.

The mean PPBS in the NN, NH and $\mathrm{HH}$ groups was $219.8 \pm$ $101.3,331.9 \pm 156.7$ and $310.6 \pm 119.4 \mathrm{mg} / \mathrm{dl}$ respectively. It was observed that PPBS correlated significantly with the CIMT $(r=0.442, p<0.01)$. The patients with postprandial hyperglycemia had significantly raised CIMT. This result was similar to that obtained by Katherine Esposito et al ${ }^{[18]}$ in 2008 , who reported statistically significant correlation of incremental glucose peak, absolute glucose peak and 2 hour glucose (postprandial blood sugar) with CIMT.

The mean serum total cholesterol in the $\mathrm{NN}, \mathrm{NH}$ and $\mathrm{HH}$ groups was $163.18 \pm 48.11,160.76 \pm 52.17$ and $158.94 \pm 57.63 \mathrm{mg} / \mathrm{dl}$ respectively.

No correlation was observed between the total cholesterol levels, either fasting $(p<0.05)$ or postprandial $(p>0.05)$, with the CIMT. Similarly, Katherine Esposito et al ${ }^{[18]}$ in 2008 also found and CIMT did not correlate with total cholesterol levels ( $r=-0.02 ; p=0.82$ ).

The mean serum $\mathrm{HDL}$ in the NN, NH and $\mathrm{HH}$ groups was 38.75 $\pm 13.37,37.78 \pm 8.80$ and $22.56 \pm 10.44 \mathrm{mg} / \mathrm{dl}$ respectively. No association was found between fasting $(p>0.05)$ and postprandial ( $p>0.05$ ) HDL levels with the CIMT which was supported by the study of Katherine Esposito et al ${ }^{[73]}$ in 2008 who reported that CIMT did not correlate with high-density lipoprotein (HDL)-cholesterol levels $(r=-0.03 ; p=0.67)$.

The mean serum LDL in the NN, NH and HH groups was 107.38 \pm $37.54,102.67 \pm 28.88$ and $86.94 \pm 49.97 \mathrm{mg} / \mathrm{dl}$ respectively.

No statistical correlation was found between the fasting and postprandial LDL levels with the CMIT ( $p>0.05)$.

Due to paucity of literature on the correlation between the LDL and CIMT and statistically insignificant correlation obtained in the present study, require further extensive studies with a vast sample size.

This non-association could be because of lab method used for finding HDL value. Our lab use Friedwald formula for calculation of LDL rather than directly measuring it. This calculation is not accurate as triglyceride level increase. ${ }^{[20]}$

The mean serum VLDL in the NN, $\mathrm{NH}$ and $\mathrm{HH}$ groups was $17.94 \pm 5.66,23.56 \pm 7.43$ and $48.75 \pm 16.09 \mathrm{mg} / \mathrm{dl}$ respectively.

There was a statistically significant correlation of CMIT with the fasting VLDL $(p<0.05)$ and postprandial VLDL $(p<0.05)$.

Gronholdt et al[ ${ }^{[21]}$ in 1996 observed a statistically significant correlation of CIMT with fasting and postprandial VLDL $(p<0.05)$ in patients with symptomatic carotid atherosclerosis $(\geq 40 \%$ carotid artery stenosis) and Susanna B et al ${ }^{[22]}$ in 1999 obtained 
significant correlation of CIMT with postprandial VLDL $(p<0.05)$ in normal population too.

Due to paucity of literature on the significant correlation between VLDL and CIMT specially in type 2 diabetes mellitus, as obtained in present study $(p<0.05)$, require further extensive studies with a vast sample size.

The mean FTG in the NN, NH and HH groups was $89.7 \pm 29$, $107.4 \pm 24.7$ and $237.3 \pm 81.9 \mathrm{mg} / \mathrm{dl}$ respectively. The mean FTG was significantly higher in $\mathrm{HH}$ group than that in $\mathrm{NN}$ and $\mathrm{NH}$ groups while there was no significant difference between the mean FTG of NN and NH groups.

ShinichiTeno et al $^{[14]}$ in 2000, observed the mean serum fasting triglycerides in the $\mathrm{NN}, \mathrm{NH}$ and $\mathrm{HH}$ groups was $111.1 \pm 39.9$, $125.3 \pm 21.3$ and $270.2 \pm 110.2 \mathrm{mg} / \mathrm{dl}$ respectively. The mean FTG was significantly higher $\mathrm{HH}$ group than that of in the NN and $\mathrm{NH}$ groups and moreover there was no significant difference between mean FTG of NN and NH groups as observed in the present study.

It was also observed that there is an increase in CIMT with the increase in FTG levels having a statistically significant correlation between CIMT and FTG levels $(p<0.01)$. CIMT was higher in the patients with fasting hypertriglyceridemia as compared to those with normal fasting triglyceride levels. This observation is supported by various authors. ShinchiTenoet al $^{[14]}$ in 2000 found that CIMT of the patients with fasting hypertriglyceridemia was greater than that of the patients with normal FTG levels $(p=0.02)$. Mori et al $^{[23]}$ in 2005 found that the CIMT values were significantly higher in diabetic patients with fasting hypertriglyceridemia as compared to that in those with normal fasting triglyceride levels. Mala Dharmalingam et al[16] $^{[1 n} 2004$ also found that fasting triglycerides correlated significantly with carotid intima-media thickness.

The mean PPTG in the NN, NH and $\mathrm{HH}$ groups was $114.9 \pm 28.2$, $192.7 \pm 38.3$ and $289.1 \pm 87.9 \mathrm{mg} / \mathrm{dl}$ respectively. The mean PPTG values in the $\mathrm{NH}$ and $\mathrm{HH}$ groups were significantly higher than that in the NN group.

ShinchiTeno et al $^{[14]}$ in 2000 observed the mean serum postprandial triglycerides in the $\mathrm{NN}, \mathrm{NH}$ and $\mathrm{HH}$ groups was $145.5 \pm 44.4,263.1 \pm 42.6$ and $391.9 \pm 23.7 \mathrm{mg} / \mathrm{dl}$ respectively. The mean PPTG values in the $\mathrm{NH}$ and $\mathrm{HH}$ groups were significantly higher than that in the NN group which resembles our observations.

It was observed that CIMT increased with increase in the PPTG levels and there exists a significant correlation between CIMT and PPTG $(p<0.01)$. this is supported by the study of Mori et al $^{[23]}$ in 2005, who concluded that in diabetic patients the CIMT values were significantly higher in patients with postprandial hypertriglyceridemia as compared to CIMT of patients with normal postprandial triglyceride levels.

\section{REFERENCES}

1. Sahay BK. (2008). Diabetology : Diabetes Mellitus - Basic Considerations. In: Shah SN et al (Editor). API Textbook of Medicine. 8th edition; Vol 2. The Association of Physicians of India; Mumbai , p.1042-1081.

2. Powers AC. (2008). Endocrinology and Metabolism:
In the present study, it was observed that although both FTG and PPTG levels are significantly correlating with CIMT but the PPTG levels $(F=20.22, r=0.67)$ were more significantly correlating with CIMT as compared to the FTG levels ( $F=8.13$, $r=0.45)$.

Also, it was observed that CIMT was higher in patients with postprandial hypertriglyceridemia despite normal fasting triglyceride levels. Thus PPTG levels were significantly correlated with CIMT in patients even with normal FTG level $(p<0.01)$.

Hence, it can be concluded that PPTG levels may be a better predictor of carotid intima media thickness that FTG in patients with type 2 diabetes. These observations were supported by ShinchiTeno et al ${ }^{[14]}$ and Chen $X$ et al ${ }^{[24]}$.

ShinchiTeno et al ${ }^{[14]}$ in 2000 , observed CIMT in the patients with postprandial hypertriglyceridemia despite normal FTG levels. Furthermore, PPTG levels were more strongly and independently correlated with CIMT and FTG levels. It was concluded that, postprandial hypertriglyceridemia, despite normal FTG levels, may be an independent risk factor for early atherosclerosis in type 2 diabetes.

Chen $X$ et $a^{[24]}$ in 2003 , observed that the CIMT in patients postprandial hypertriglyceridemia was significantly greater than that in patients with postprandial normal-triglyceridemia $(p<0.05)$, which remained significant after adjustment for fasting triglyceride levels, it was concluded that postprandial hypertriglyceridemia may be an independent risk factor of early atherosclerosis in type 2 diabetes.

\section{CONCLUSION}

The present study concludes as under:

1. That both fasting and postprandial triglyceride levels correlate significantly with carotid intima media thickness. But, the correlation of postprandial triglyceride levels with carotid intima media thickness is better than that of fasting triglyceride levels with carotid intima media thickness.

2. The postprandial hypertriglyceridemia despite normal fasting triglyceride level can be considered as an independent risk factor for atherosclerosis in type 2 diabetes mellitus. Hence, evaluating not only for the fasting triglyceride levels but also the postprandial triglyceride levels during the clinical assessment of patients with type 2 diabetes mellitus is essential.

3. Incidentally, carotid intima media thickness had statistically significant correlation with-
i. Age of the patient
ii. Duration of diabetes
iii. Postprandial blood sugar levels
iv. Fasting and postprandial VLDL levels

Diabetes Mellitus. IN: Fauci et al (Editor), Harrison's Principles of Internal Medicine, 17th edition; Vol-2. Mc Graw Hill Medical, New York, p.2275-2304 .

3. Tomkin GH. ( 2010 ). Atherosclerosis, diabetes and lipoproteins. Expert Rev Cardiovasc The , Jul; 8(7): 101529. 
4. Luther T ClarkE. (2007). Cardiovascular disease and diabetes: An epidemiological overview; Luther T Clarke, Cardiovascular disease and diabetes. Tata MC graw Hill edition , 2-3.

5. Gracia MJ, Mc Namara PM, Gordon T, Kannel WB. (1974). Mordibity and mortality in Diabetics in Framingham population, Sixteen year follow-up study. Diabetes, 23:105-11.

6. Fagan TC, Sowers J. (1999). Type 2 diabetes mellitusgreater cardiovascular risks and greater benefits of Therapy . Arch Intern Med, 159:1033-34.

7. Haffiner SM, Lehto'S, Ronnemaa T, Pyorala K, Laakso M. (1998). Mortality from coronary heart disease in subjects with type 2 diabetes and in non-diabetic subjects. N Engl J Med , 339:229-34.

8. Fontbonne A. (1991). Relation between diabetic dyslipoproteinemia and coronary heart disease risk in non-insulin dependent diabetes. Diabetes Metab Rev , 7:179-89.

9. Fontbonne A, Eschewege E, Cambien F, et al. (1994). Hypertriglyceridemia as a risk factor for coronary heart disease mortality in subjects with impaired glucose tolerance or diabetes: Results from 11 years follow up of the Paris Prospective study. Diabetologia , 1989;32:30004.

10. Jonathan Valabhji and Robert S Elkeles. (2003). Dyslipodaemia in type 2 diabetes: epidemiology and biochemistry. British Journal of Diabetes \& Vascular Disease. 3:184-9.

11. Michael Millar, Neil J. Store, Christie Ballantyne et al. (May 21, 2014). Triglyceride and Cardiovascular Disease - A Scientific Statement from American Heart Association Circulation. Vol 123, Issue 20.

12. Iglesias del Sol A, Bots ML, Grobbee DE. Hofman A, Witterman JC. (2002). Carotid intima-media thickness at different sites: relation to incident myocardial infarction. The Rotterdam Study. Eur Heart J , 2002;23(12):934-940

13. Lars A, Solberg and Douglas A et al. (Eggen:). Localization and Sequences of Development of Atherosclerotic Lesions in the Carotid and Vertebral Arteries. Circulation , 1971: 711-724.

14. Shinichi T, Yuko U, Hirotaka N, et al. (2000). Association of Postprandial Hypertriglyceridemia and Carotid Intima-Media Thickness in patient with Type 2 diabetes. Diabetes Care , 2000:23:1401-6.

15. Ahmad J, Hameed B, Ahmad I, Das G. Mohammad
A Siddiqui. (2005). Association of postprandial hypertriglyceridemia and carotid intima media thickness in patients with type 2 diabetes. Vol. 51. DEC 2003: 1227, Vol. 51. DEC 2003: 1227.

16. Mala Dharmalingam, Neeta $R$ Deshpande, Sudha Vidyasagar. (2004). Triglyceride levels and its correlation with carotid intima media thickness. INT. J. DIAB. DEV. COUNTRIES, Vol. 24

17. Mohan V, Ravikumar R, Shanthi Rani S, Deepa R. (2000). Intimal media thickness of the carotid artery in South Indian diabetic and non-diabetic subjects: the Chennai Urban Population Study (CUPS). Diabetologia , 2000;43(4):494-499.

18. Esposito K, Ciotola M, Carleo D, Schisano B, Sardelli L, Di Tommaso D, Misso L, Saccomanno F, Ceriello A, Giugliano D. (2008). Post-meal glucose peaks at home associate with carotid intima-media thickness in type 2 diabetes. J Clin Endocrinol Metab , 93(4):1345-1350.

19. Abdelghaffar S, El Amir M, El Hadidi A, El Mougi F. (2005). Carotid intima media thickness: An index for subclinical atherosclerosis in type 1 diabetes. J Trop Pediatr , 52(1);39-45.

20. Subramarian K, Shiriram M, Bharath Ramji et al. (2014 Jul-Aug). LDL Cholesterol; Friedewald calculation versus direct measurement, Study from a large indian laboratory database. Indian J Endosrinal Matab, 18(4) 502-504

21. Gronholdt M-L, Nordesgaard BG, Nielsen TG, Sillesen H. (1996). 1Echolucent carotid artery plaques are associated with elevated levels of fasting and postprandial triglyceride-rich lipoproteins. Stroke. 27:2166-2172.

22. Susanna B, Boquist S, Ruotilo G, Tang R, Bjorkegren J, Bond MG, de Faire U, Karpe F, Hamsten A. (1999). Alimentary lipemia, postprandial triglyceride- rich lipoprotein and common carotid intima-media thickness in healthy, middle-aged men. Circulation , 100:723-728.

23. Mori $\mathrm{Y}$, Itoh $\mathrm{Y}$, Komiya $\mathrm{H}$, et al. (2005). Association between postprandial remnant-like particle triglyceride (RLP-TG) levels and carotid intima-media thickness (IMT) in Japanese patients with type 2 diabetes: Assessment by meal tolerance tests (MTT) Endocrine. 28:157-63.

24. Cheng Xiang, Tian Haoming and Liu Rui. (2003). Association between fasting and postprandial triglyceride levels and carotid intima-media thickness in type 2 diabetic patients. Chin Med J , 116(12): 19331935. 